\title{
DEGRADATION OF PHENOLIC COMPOUNDS IN WATER BY NON-THERMAL PLASMA TREATMENT
}

\author{
Hsu-Hui Cheng ${ }^{1}$, Shiao-Shing Chen ${ }^{1}$ Kazuharu Yoshizuka ${ }^{2}$, \\ Yung-Chih Chen ${ }^{3}$
}

\author{
${ }^{1}$ Institute of Environment Engineering and Management, National Taipei \\ University of Technology, Taipei, Taiwan; \\ ${ }^{2}$ Faculty of Environmental Engineering, The University of Kitakyushu Hibikino, \\ Kitakyushu, Japan; \\ ${ }^{3}$ Institute of Nuclear Energy Research, Atomic Energy Council, \\ Village, Longtan Township, Taoyuan Country, Taiwan
}

Recieved 24.02.2011

A stainless-steel hollow needle type anode was used in the reactor to treat industrial wastewater by gas-liquid phase non-thermal plasma by corona discharge. The results showed that the short electrode gap, $1 \mathrm{~cm}$, has a higher plasma energy density which improves the removal of the phenolic derivatives, reaching $100 \%$ after about $60 \mathrm{~min}$. The $\mathrm{H}_{2} \mathrm{O}_{2}$ concentration was higher in the discharge system when the content of oxygen was increased. The efficiency of the phenol removal by chemical oxygen demand was only 10 - 31\% after 60 minutes. The identifie dinterme diates were catechol, hydroquinone, 1,4-benzoquinone, 2-nitrophenol,1,2-benzenedicarboxylic acid, diphenylmethanone, 2methyl-hydroquinone, 2-methyl-1,4-bezoquinone, and trace amounts of organic.

Keywords: corona discharge, intermediates, non-thermal plasma, phenolic.

A stainless-steel hollow needle type anode was used in the reactor to treat industrial wastewater by gas-liquid phase non-thermal plasma (NTP) by corona discharge. The results showed that the short electrode gap, $1 \mathrm{~cm}$, has a higher plasma energy density which improves the removal of the phenolic derivatives, reaching $100 \%$ after about 60 minutes. The $\mathrm{H}_{2} \mathrm{O}_{2}$ concentration was higher in the discharge system when the content of oxygen was increased. The efficiency of the phenol removal by chemical oxygen demand was only $10-31 \%$ after 60 minutes. The identified intermediates were catechol, hydroquinone, 1,4-benzoquinone, 2nitrophenol, 1,2-benzenedicarboxylic acid, diphenylmethanone, 2-methylhydroquinone, 2-methyl-1,4-bezoquinone, and trace amounts of organic.

\section{INTRODUCTION}

Recently, several advanced oxidation processes (AOPs) have been studied to remove organic compounds from wastewater. Most AOP, 
such as $\mathrm{UV} /$ Fenton oxidation, electron-beam irradiation, and $\mathrm{TiO}_{2}$ photocatalysis processes generate more active species in solution $\left(\mathrm{OH} \cdot \mathrm{O}_{3}\right.$ and $\mathrm{H}_{2} \mathrm{O}_{2}$ etc), but most commonly the hydroxyl radical $(\mathrm{OH} \cdot)$ is the active species [1-3]. However, the complete mineralization of contaminants by AOP requires long time of reaction times and high concentrations of oxidants. In addition, less reactive intermediates are often produced which can inhibit the degradation of the parent target compound [4]. This is because the generation of hydroxyl radicals is generally slow [5]. Compared with AOP approaches, non-thermal plasma (NTP) can achieve greater output and higher efficiency. An NTP process can remove chemical and biological wastes from gas, liquid, and solid states samples [6]. It has also been proven to work over a large dynamic range. The method can decompose both high- and lowconcentration organic wastewater even at high flux [7]. The NTP discharge process directs a large amount of high energy electrons and active species towards the oxidation of dissolved organic molecules $[5,7,8]$.

A number of studies have been conducted using NTP for the removal of organic compounds from wastewater. Chen et al. [5] reported that high voltages and gas volumes increase the efficiency of the phenol removal. Sugiarto and Sato [1] showed that addition of oxidants to the NTP enhanced the degradation of organic compounds. Also, Hao et al. [9] have reported on combining $\mathrm{TiO}_{2}$ and NTP in a process for the degradation of the organic pollutant 4-chlorophenol in water. These studies mainly focused on the use of NTP process with metal oxide or oxidant additives, different discharge types, and various gas sources for the removal of organic compounds from wastewater $[1,5,9-11]$. However, there has been no research focused on the oxidation efficiency of the NTP technique. Only few papers have been published focusing the efficiency of oxidation (3c) by electrochemical methods for wastewater treatment.

The oxidation process caused by NTP involved indirect oxidation reactions in close proximity to the electrode, and hydroxyl radicals and strong oxidants are generated by oxidation of the supporting electrolyte [12]. The values of oxidation efficiency can be calculated from the slope of a graph of the total organic carbon (TOC) plotted against the chemical oxygen demand (COD) [12]. These values can then be used to evaluate the extent of oxidation, such as the mineralization efficiency (complete oxidation to $\mathrm{CO}_{2}$ ). For this reason, this study self-developed a new corona discharge system (as an example NTP reactor) to evaluate the extent of oxidation. Based on the characteristics desired, the corona discharge reactor has been designed to degrade organic compounds in wastewater at a high voltage at atmospheric pressure. A stainless-steel hollow needle for directing a gas stream to the anode has been incorporated to achieve the correct gas-electricity mixture in the NTP system and to reduce the power consumption. In this study, three simple molecules compounds (namely phenol, catechol, and o-cresol) acting as three degradation pathways occurred by electrophilic attack of hydroxyl radical are selected 
as model organic compounds due to their common general formula of phenolic structures in order to understand the efficiency of their oxidation.

Since none of the above study has compared the pathways with byproducts of these three types of phenolic using the NTP system, this study describes the degradation of aqueous phenols by gas-liquid phase NTP with corona discharge under water. The focus is on establishing the extent of the oxidation and the use of theoretical models to obtain the rate of COD removal in the oxidation processes. The effects of current, electrode gap, oxygen usage, and intermediates were also investigated.

\section{Experimental}

The experimental setup is shown in Fig. 1. A pulsed power supply (Glassman High Voltage, Inc, EK Series $600 \mathrm{~W}$ ) was used to provide $0-30 \mathrm{kV}$ pulses at a frequency of $500 \mathrm{kHz}$ through the high voltage discharge electrode.

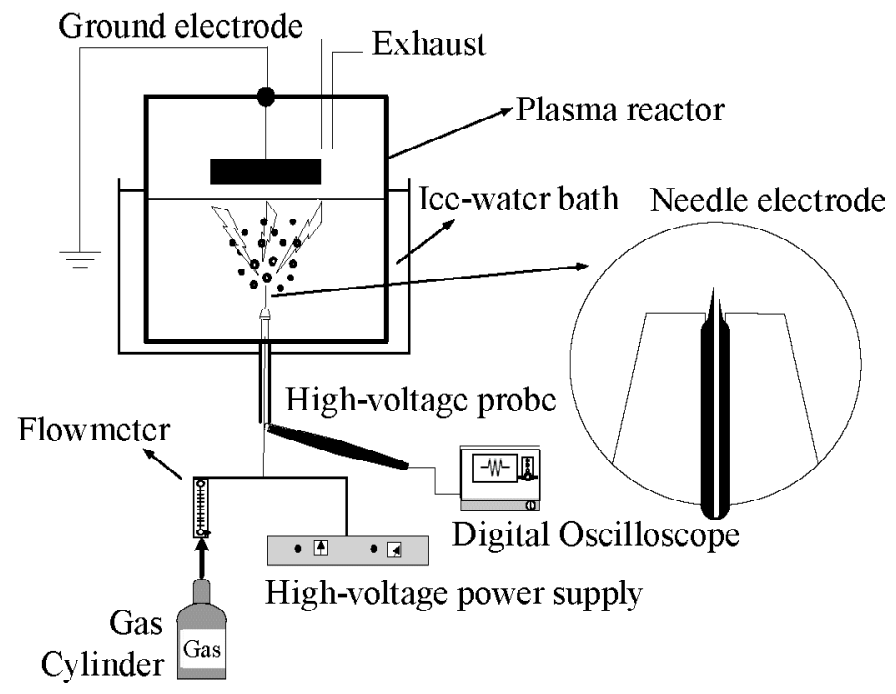

Fig. 1. Schematic diagram of the experimental set-up.

The output voltage and current were measured with a high-voltage probe (Tektronix P6015A) and a pulsed current probe (Pearson Electronics M411), respectively. The discharge parameters were also monitored on a digital oscilloscope (Qmax UM2202). The needle-plate electrode was placed at the center of a cylindrical quartz tube (60/55 $\mathrm{mm} \mathrm{OD} / \mathrm{ID})$ for the generation of a corona discharge in the water. A hollow stainless-steel needle was used as the discharge electrode. The point electrode of the hollow needle, ca. $3.2 \mathrm{~cm}$ long, was installed in the center of 
cylindrical reactor above the bottom of the vessel. Only the conical tip of the point electrode was in contact with the sample. A $40 \mathrm{~mm}$ diameter stainless-steel ground plate was installed on top of the reactor, opposite the needle discharge electrode. The distance between the ground plate and needle electrode was adjustable. The reaction temperamental range was set in the range of 25 to $50{ }^{\circ} \mathrm{C}$, and the gas flow rate was set at $150 \mathrm{ml} / \mathrm{min}$.

Chemical analysis. Materials. The headspace solid-phase micro extraction (SPME) syringe needle for manual sampling and the polyacrylate fiber were purchased from Supelco. Phenol (purity $>99.5 \%$ ), pyrocatechol (purity $>99.0 \%$ ) and ocresol (purity $>99.0 \%$ ) were purchased from Merck and Yakuri. Sodium chloride (purity $>99.8 \%$ ) was purchased from Nihon Shiyaku. Deionized water was prepared by a Hondwen Reverse Osmosis/Deionization System. The test solutions of the three phenols $\left(\mathrm{C}_{0}=100 \mathrm{mg} / \mathrm{L}\right)$ were prepared by diluting standard solutions to the desired concentrations, and stored in a refrigerator until use.

GC/MS conditions. All gas chromatographic analyses were performed on an Agilent Technologies 6890N gas chromatograph, equipped with an Agilent Technologies $5973 \mathrm{~N}$ selective mass detector. Helium was used as the carrier gas at a flow-rate of $1 \mathrm{ml} / \mathrm{min}$. The injection port temperature was set to $280^{\circ} \mathrm{C}$. The electron ionization (EI) and the interface temperatures were set to 230 and $280{ }^{\circ} \mathrm{C}$, respectively. The MS was operated in total ion current (TIC) mode, scanning from $\mathrm{m} / \mathrm{z} 45$ to 280 . For quantitative determination, the MS was operated in the SIM mode. All separations were performed with a $30 \mathrm{~m}$ RTX-5MS column (Restek), with a $0.25 \mathrm{~mm}$ film and $0.25 \mathrm{~mm}$ ID. New polyacrylate fiber was conditioned in the injection port of the gas chromatograph at $280^{\circ} \mathrm{C}$ for $25 \mathrm{~min}$. After use, the polyacrylate fibers were cleaned by heating to $280^{\circ} \mathrm{C}$ for $5 \mathrm{~min}$ prior to extraction.

Analytical procedure. The $5.4 \mathrm{~g}$ of $\mathrm{NaCl}$ was added to a $50 \mathrm{ml}$ headspace vial containing $20 \mathrm{ml}$ of plasma-treated sample. A magnetic stirrer was used to stir the mixture at $700 \mathrm{rpm}$. The vial was then placed on a heat/stir plate. The polyacrylate fiber was introduced through the septum and kept in the headspace of the vial at $40^{\circ} \mathrm{C}$ for $20 \mathrm{~min}$. During the extraction, the samples were stirred at $700 \mathrm{rpm}$. Subsequently, the polyacrylate fiber was withdrawn and inserted into the SPME syringe needle, removed from the sample vial and immediately inserted into the GC injection port for desorption. Desorption was conducted at $280^{\circ} \mathrm{C}$ for $25 \mathrm{~min}$. Finally, the phenolic compounds were analyzed and each sampling was performed in triplicate. Additionally, TOC measurements were performed using an Aurora 1030C TOC Analyzer (O.I. Analytical Corporation). COD was determined by the colorimetric method (standard method of Taiwan, W520-51A).

The ion chromatography (IC) measurement was performed using an ICS-90 Analyzer(Dionex Corporation). 


\section{RESULTS AND DISCUSSION}

Degradation assays. The effect of electrode distance and variation of pH with conductivity. The electrode distance was varied between 1 and $3 \mathrm{~cm}$, and the effects of this on the degradation of different phenols from aqueous solution are shown in Fig. 2. The results showed a significant decrease in the TOC of the phenols at narrower electrode gaps, especially at close to a distance of $1 \mathrm{~cm}$. The phenol, catechol, and $o$-cresol solutions were treated for 60 minutes in gas-liquid phase NTP with a corona discharge system and showed a decrease in concentration from $76.60,65.45$ and $77.78 \mathrm{mg} / 1$ to $4.60,0.0131$ and $0.6634 \mathrm{mg} / \mathrm{l}$, respectively $(d=1.0 \mathrm{~cm})$. The narrow gap is believed to produce higher plasma energy density between the electrodes. This allows the system to deposit more energy into the solution and remove more of the phenolic contaminants. In general, the TOC decreases with increasing treatment time, which indicates that the degraded organic carbon is being converted into $\mathrm{CO}_{2}[3,5]$. Although TOC were almost completely removed in Fig. 2, only 20 to $31 \%$ degradations of the COD were observed. In theory, the degradation of TOC is directly correlated with the degradation of COD. However, according to Wang et al. [13], the glow discharge plasma could react with water and contribute to the generation of $\mathrm{H}_{2} \mathrm{O}_{2}$. Since $\mathrm{H}_{2} \mathrm{O}_{2}$ is a reducing agent which also consume potassium dichromate in the COD measurement, higher COD was seen in their study. Consequently, in Fig. 2, the low COD removal along with high COD removal is an indication of the generation of $\mathrm{H}_{2} \mathrm{O}_{2}$ in our system, and the amount of generated $\mathrm{H}_{2} \mathrm{O}_{2}$ will be discussed in the later section.

Fig. 3 shows the variation of $\mathrm{pH}$ and conductivity during the degradation of different phenols when exposed to air. After $10 \mathrm{~min}$., the $\mathrm{pH}$ of solution decreased dropped rapidly from initial 5.7, 5.6, and 5.8 to $2.9,2.10$, and 2.12, respectively, and then remained almost constant. This can be explained by carboxylic acids being generated in the reaction process. Sun et al. [14] similarly reported that oxidation by plasma tends to increase the acidity of the solution. In addition, we also observe that the formation of nitric acid $\left(\mathrm{HNO}_{3}\right)$ in the presence of different phenols solutions (namely phenol, catechol, and $o$-cresol), the concentration of $\mathrm{HNO}_{3}$ was 299.7, 319.9 , and $179.6 \mathrm{mg} / 1$, respectively. Primarily due to air used as the carrier gas, the dissociation of nitrogen in air which subsequently formed the $\mathrm{HNO}_{3}$ in solution, leads to the $\mathrm{pH}$ decrease and conductivity increase during plasma treatment. Yan et al. [15] similarly reported that the air is used as feeding gas lead to the decreasing of $\mathrm{pH}$, and the main reason was the dissociation of nitrogen oxides as $\mathrm{HNO}_{3}$ into the liquid phase. 

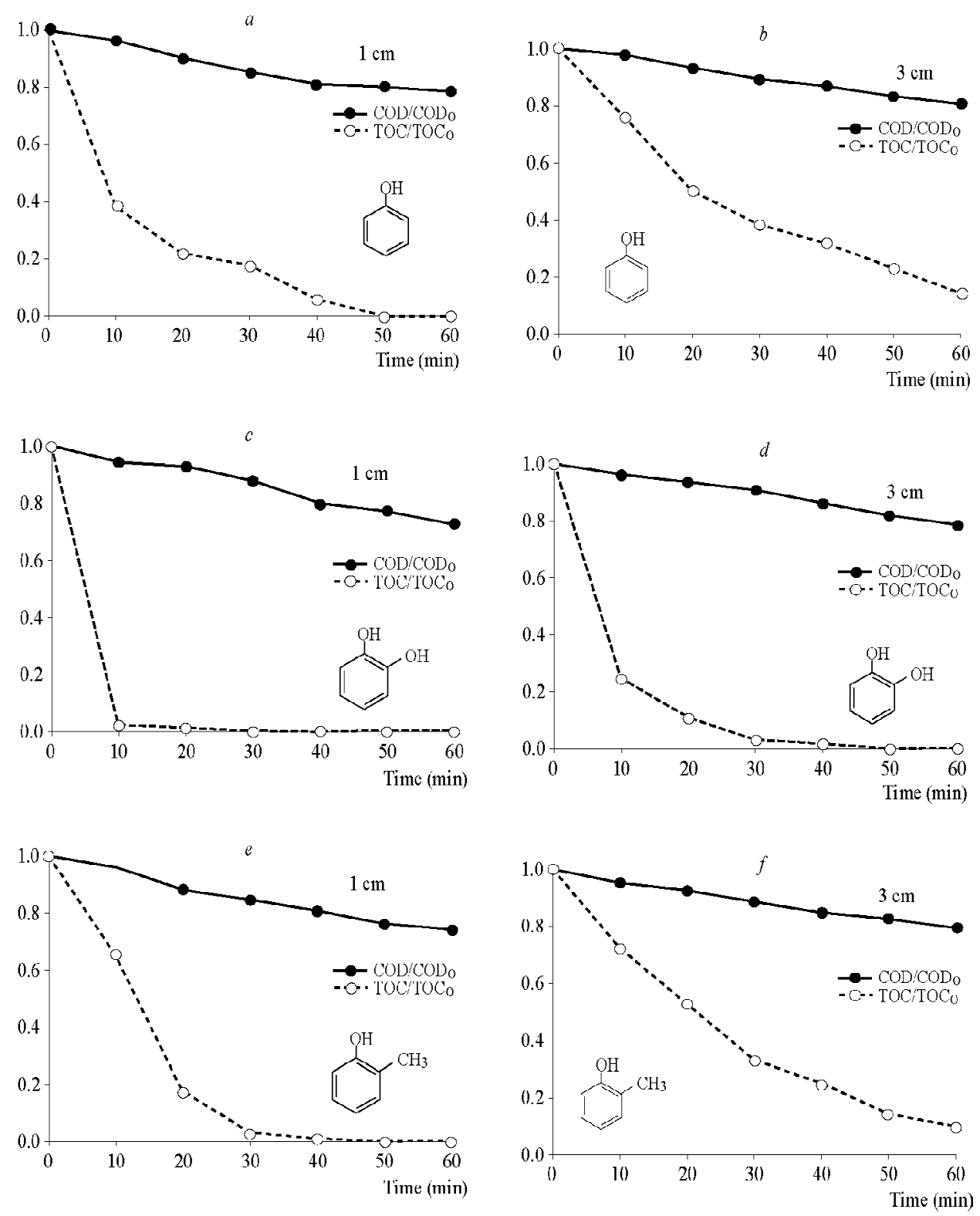

Fig. 2. The effect of the electrode distance on the removal of different phenols over time (operating conditions: $\mathrm{K}=9 \mathrm{kV} ; \mathrm{U}=6 \mathrm{~mA} / \mathrm{cm}^{2} ; Q_{\text {air }}=150 \mathrm{ml} / \mathrm{min}$; $\left.C_{0}=100 \mathrm{mg} / \mathrm{L}\right) ; a-b-$ phenol, $c, d$-catechol, $e-f$-o-cresol. 


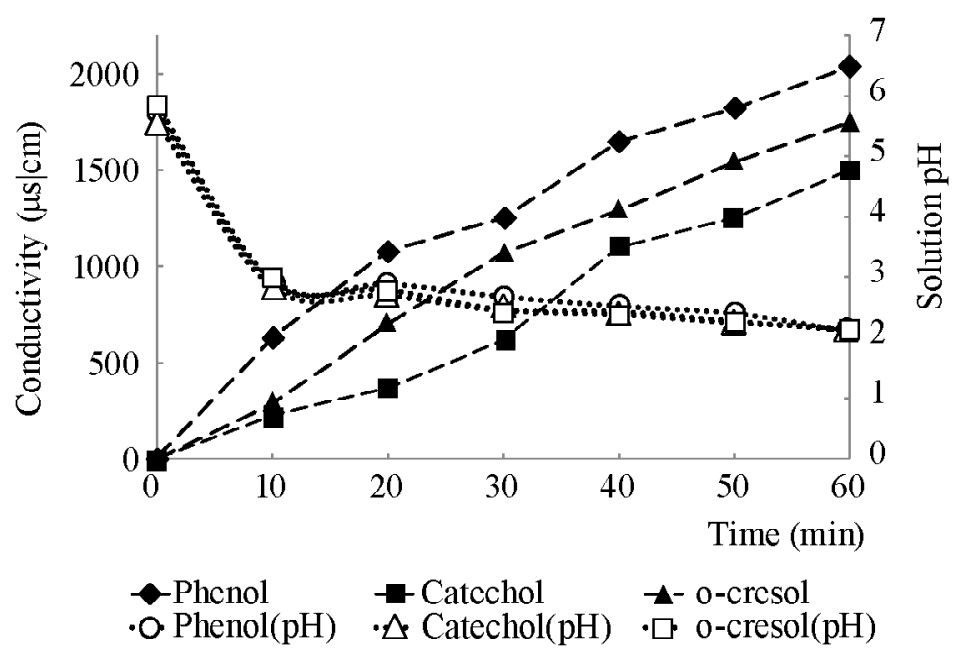

Fig. 3. The variation of $\mathrm{pH}$ and conductivity during the degradation of different phenols in the corona discharge process (operating conditions: $K=9 \mathrm{kV}$; $U=$ $\left.6 \mathrm{~mA} / \mathrm{cm}^{2} ; d=1.0 \mathrm{~cm} ; Q_{\text {air }}=150 \mathrm{ml} / \mathrm{min} ; C_{0}=100 \mathrm{mg} / \mathrm{L}\right)$.

Consequently, the $\mathrm{pH}$ and conductivity variation can be partly accounted by the formation of acids and ions formed from the dissolution of nitrogen oxides, as expressed in the following:

$$
\begin{aligned}
& \mathrm{N}_{2}{ }^{*}+\mathrm{O}_{2} \rightarrow 2 \mathrm{NO}^{*}, \\
& 2 \mathrm{NO}+\mathrm{O}_{2} \rightarrow 2 \mathrm{NO}_{2}^{*}, \\
& \mathrm{NO}+2 \mathrm{H}_{2} \mathrm{O} \rightarrow \mathrm{NO}_{3}^{-}+4 \mathrm{H}^{+}+3 e^{-}, \\
& \mathrm{NO}_{2}+\mathrm{OH}^{*}+\mathrm{M} \rightarrow \mathrm{HNO}_{3}+\mathrm{M}, \\
& 2 \mathrm{NO}_{2}+\mathrm{H}_{2} \mathrm{O} \rightarrow \mathrm{HNO}_{2}+\mathrm{HNO}_{3}, \\
& \mathrm{NO}_{+}+e^{-} \rightarrow \mathrm{NO}^{+}+2 e^{-}, \\
& \mathrm{NO}^{+}+\mathrm{H}_{2} \mathrm{O} \rightarrow \mathrm{H}^{+}+\mathrm{HNO}_{2} .
\end{aligned}
$$

The effect of applied current. The effects of varying the applied current were investigated further on phenol, as shown in Fig. 4. The phenol degradation kinetics were fitted with a first order curve. The pseudo-first order rate constants at various currents are shown in Fig. 4 (a). The rate constants were 0.0087, 0.0208, and $0.07321 / \mathrm{min}$ at current densities of 2,4 , and $6 \mathrm{~mA} / \mathrm{cm}^{2}$, respectively. With a high 
current, the electron transfer rate was high and the chemical reaction rate on the anode increased, which resulted in a higher degradation efficiency of the phenol molecules. In addition, the removal efficiency of phenol $\left(\mathrm{C} / \mathrm{C}_{0}\right)$ at $6 \mathrm{~mA}$ was the highest, reaching 100\% after about 60 minutes. At current densities greater than 6 $\mathrm{mA}$, the energy is transformed into heat [16]. Hence, $6 \mathrm{~mA} / \mathrm{cm}^{2}$ was selected as the optimum current density. Fig. $4(b-d)$ shows the removal efficiency of TOC/COD at different current densities ranging from 2 to $6 \mathrm{~mA}$. The phenol removal efficiency as measured by TOC was $56 \%-98 \%$, but the removal efficiency as measured by COD was only $10-31 \%$ after $60 \mathrm{~min}$. These results clearly indicate stable intermediates are being formed during the oxidation process.
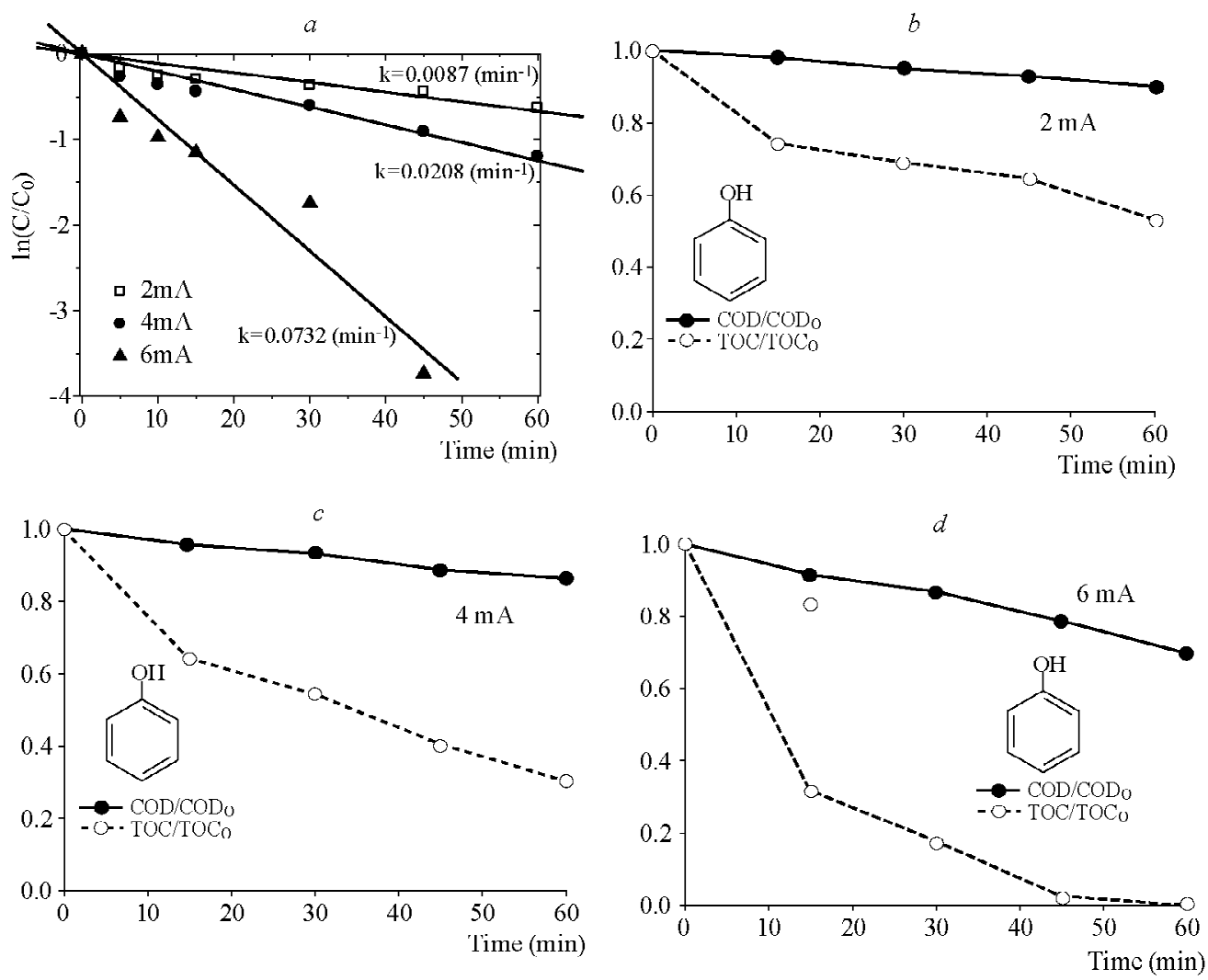

Fig. 4. The effects of varying the current density on the removal of phenol over time (operating conditions: $d=1.0 \mathrm{~cm}, Q_{\text {air }}=150 \mathrm{ml} / \mathrm{min}, C_{0}=100 \mathrm{mg} / \mathrm{L}$ ).

The effect of oxygen content. Fig. 5 shows the degradation of phenol increased in the presence of higher concentrations of oxygen. At $30 \%$ oxygen, the phenol was completely removed by the corona discharge after $40 \mathrm{~min}$. Therefore, the energy efficiency is at the lowest when the oxygen concentration is $0 \%$. The results in Fig. 5 can be analyzed to obtain the linear equation $Y_{k o b s}=0.0093\left(\mathrm{O}_{2} \%\right)+0.0055$ with $R^{2}=0.918$ for oxygen concentrations from 0 to $30 \%$. This indicates that the higher 
oxygen concentrations in the corona discharge system generate additional $\mathrm{O}_{3}$, because the UV radiation from the plasma can enhance both the degradation of organic compounds by $\mathrm{O}_{3}$ and the formation of $\mathrm{OH}$ radical, according to the following reactions:

$$
\begin{aligned}
& \mathrm{O}_{2}+\mathrm{O} \cdot \rightarrow \mathrm{O}_{3}, \\
& \mathrm{O}_{3}+\mathrm{H}_{2} \mathrm{O} \rightarrow \mathrm{H}_{2} \mathrm{O}_{2}, \\
& \mathrm{H}_{2} \mathrm{O}_{2}+h v \rightarrow \mathrm{OH} \cdot+\mathrm{OH} .
\end{aligned}
$$

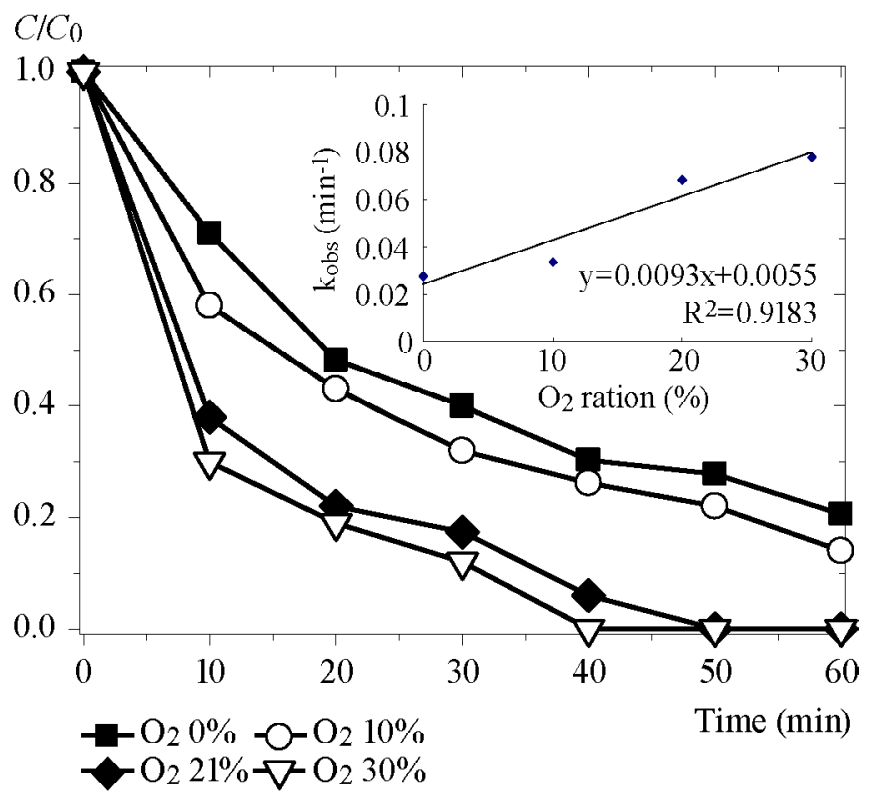

Fig. 5. The effect of oxygen concentration on the degradation of phenol over time Inset: the degradation rate constant $(k)$ versus oxygen percentage and a fitted straight line (operating conditions: $d=1.0 \mathrm{~cm}, Q_{\text {air }}=150 \mathrm{ml} / \mathrm{min}, C_{0}=$ $100 \mathrm{mg} / \mathrm{L})$.

Fig. 6 shows that as the oxygen content increases, the $\mathrm{H}_{2} \mathrm{O}_{2}$ concentration also increases to a maximum of $42 \mathrm{mg} / \mathrm{L}$ in $30 \%$ oxygen from $13 \mathrm{mg} / \mathrm{L}$ in the oxygen free case. The results were analyzed to give the linear equation $Y_{\mathrm{H}_{2} \mathrm{O}_{2}}=0.9682\left(\mathrm{O}_{2} \%\right)+$ 12.712 with an $R^{2}=0.9944$ for the range of oxygen concentrations from 0 to $30 \%$. According to the literature, higher $\mathrm{H}_{2} \mathrm{O}_{2}$ concentrations are beneficial for the removal of organic compounds [17] $\mathrm{H}_{2} \mathrm{O}_{2}$ with UV radiation, generated by the discharge process, was also main source of $\mathrm{OH}$ radical in related systems [18]. 


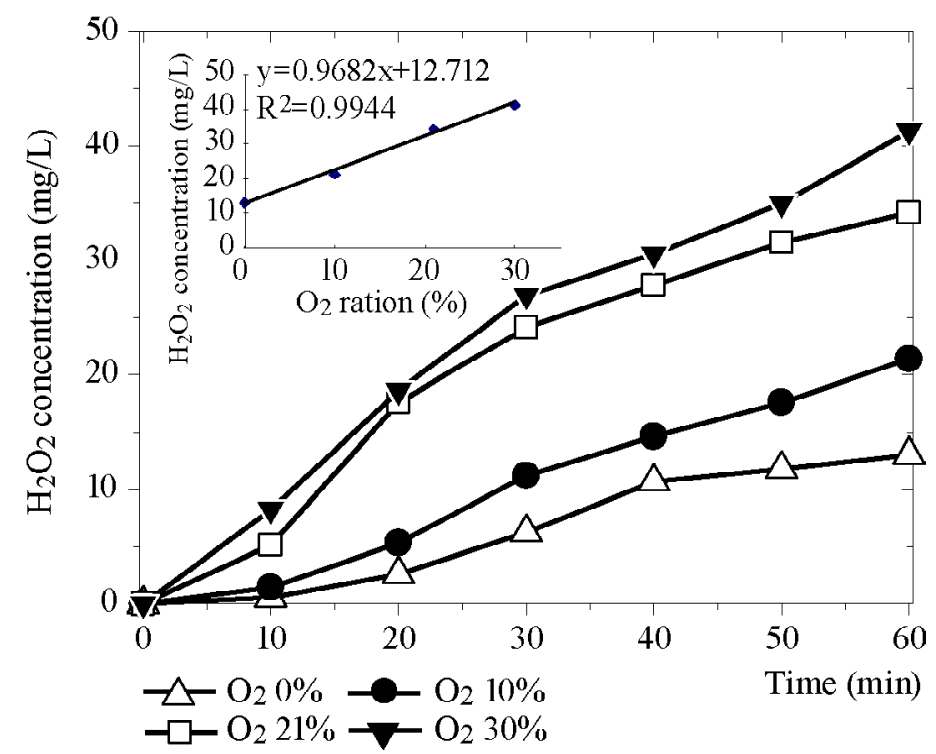

Fig. 6. $\mathrm{H}_{2} \mathrm{O}_{2}$ concentration against the discharge time Inset: the $\mathrm{H}_{2} \mathrm{O}_{2}$ concentration versus oxygen percentage and the fitted straight line (operating conditions: $d=1.0 \mathrm{~cm} ; Q_{\text {air }}=150 \mathrm{ml} / \mathrm{min} ; C_{0}=100 \mathrm{mg} / \mathrm{L}$ ).

Evaluation of oxidation efficiency. With these results, the efficiency of oxidation ( $\eta \mathrm{c}$ ) can now be estimated from the rate of decrease in the TOC compared with that of the COD as determined by the $d \mathrm{TOC} / d \mathrm{COD}$ ratio. The $\eta \mathrm{c}$ model has been developed by Pacheco et al. [12], to describe the rate of COD removal in the oxidation processes of organic compounds. This $3 \mathrm{c}$ model is described by:

$$
\eta \mathrm{c}=\frac{32}{12}\left(\frac{n}{4 x}\right) \frac{d \mathrm{TOC}}{d \mathrm{COD}}
$$

where $n$ is the number of electrons transferred to the electrode for the complete oxidation of the organic solute, and $x$ is number of carbon atoms in the organiccompound. Hence, the oxidation efficiency can be calculated from the slope of a plot of TOC vs. COD, if $n$ and $x$ are known. In multi-component systems, however thiswill not be the case. In addition, $\eta \mathrm{c}$ only equals one where the only products formed are $\mathrm{CO}_{2}, \mathrm{H}_{2} \mathrm{O}_{2}$ and $\mathrm{O}_{2}$. Compounds containing moieties which cannot be oxidized to one of these products (for example, thiols and nitriles) will never achieve $100 \%$ efficiency by this model. In this study, phenol, catechol, and $o$-cresol were chosen specifically so that $\eta c$ can be identified as the efficiency of mineralization of the whole compound, since the oxidation leads to complete mineralization, according to the following equation: 


$$
\mathrm{C}_{x} \mathrm{H}_{2} \mathrm{O}_{z}+(2 x-z) \mathrm{H}_{2} \mathrm{O} \rightarrow x \mathrm{CO}_{2}+(4 x+y-2 z) \mathrm{H}^{+}+(4 x+y-2 z) e^{-} .
$$

The oxidation efficiencies ( $\eta \mathrm{c}$ ) of the degradation of phenol, catechol, and $\mathrm{o}$-cresol are listed in Table 1 . The $\eta \mathrm{c}$ of three phenols where are superior at an electrode distance of $1 \mathrm{~cm}$ over that of $3 \mathrm{~cm}$. It also can be observed that $\eta$ for catechol was significantly higher than the other two phenols. Although $100 \%$ of the phenolic compounds were degraded by the corona discharge system within a short period of due time, the efficiency of mineralization did not increase significantly. This result indicates that the oxidation processes of these phenolic compounds form stable intermediates. The intermediates will be analyzed by GC/MS later.

Table 1. The oxidation efficiency ( $\eta c$ ) of the three phenols, according to Eq. (11)

\begin{tabular}{|c|c|c|c|c|c|c|c|}
\hline Sample & $x$ & $y$ & $z$ & $n$ & $\begin{array}{c}(32 / 12) \times \\
(n / 4 x)\end{array}$ & $\begin{array}{c}\eta \mathrm{c} \\
(d=1 \mathrm{~cm})\end{array}$ & $\begin{array}{c}\eta \mathrm{c} \\
(d=3 \mathrm{~cm})\end{array}$ \\
\hline Phenol & 6 & 6 & 1 & 28 & 3.1111 & 0.926 & 0.823 \\
\hline Catechol & 6 & 6 & 2 & 26 & 2.8889 & 0.997 & 0.981 \\
\hline$o$-Cresol & 7 & 8 & 1 & 34 & 3.2381 & 0.984 & 0.875 \\
\hline
\end{tabular}

Note: The current density was $6 \mathrm{~mA}$ for all of these measurements.

Possible degradation pathways. GC/MS analysis was used to explore the possible degradation pathways. Additionally, formic, acetic, and trace amounts of other organic acids were identified by IC measurements. The results of these analyses are summarized in Table 2. Consequently, a possible mechanism for the degradation of phenols is presented in Fig. 7 based on these results. The main intermediates derived from phenol (Fig. 7, a) are catechol, hydroquinone, 1,4-benzoquinone, and 2-nitrophenol, along with trace amounts of formic and acetic acids. Among possible chemically active species which contribute to the degradation of phenols in the gasliquid phase NTP, OH radicals and ozone are expected to be the most important species, and these species are proposed to be generated above the water surface by the coronal discharge $[10,19]$. Oxidation by $\mathrm{OH}$ radicals has been previously shown to be the primary step in the degradation of phenol by the liquid phase discharge $[10,17,20,21]$. This process by $\mathrm{OH}$ radical attack onto aromatic ring, oxidizing the phenol is first to catechol. It is also possible for this to occur by electrophilic attack by either the hydroxyl radical or ozone [22, 23]. 
Table 2. Intermediates identified by GC/MS (quality match $>80 \%$ ) and IC

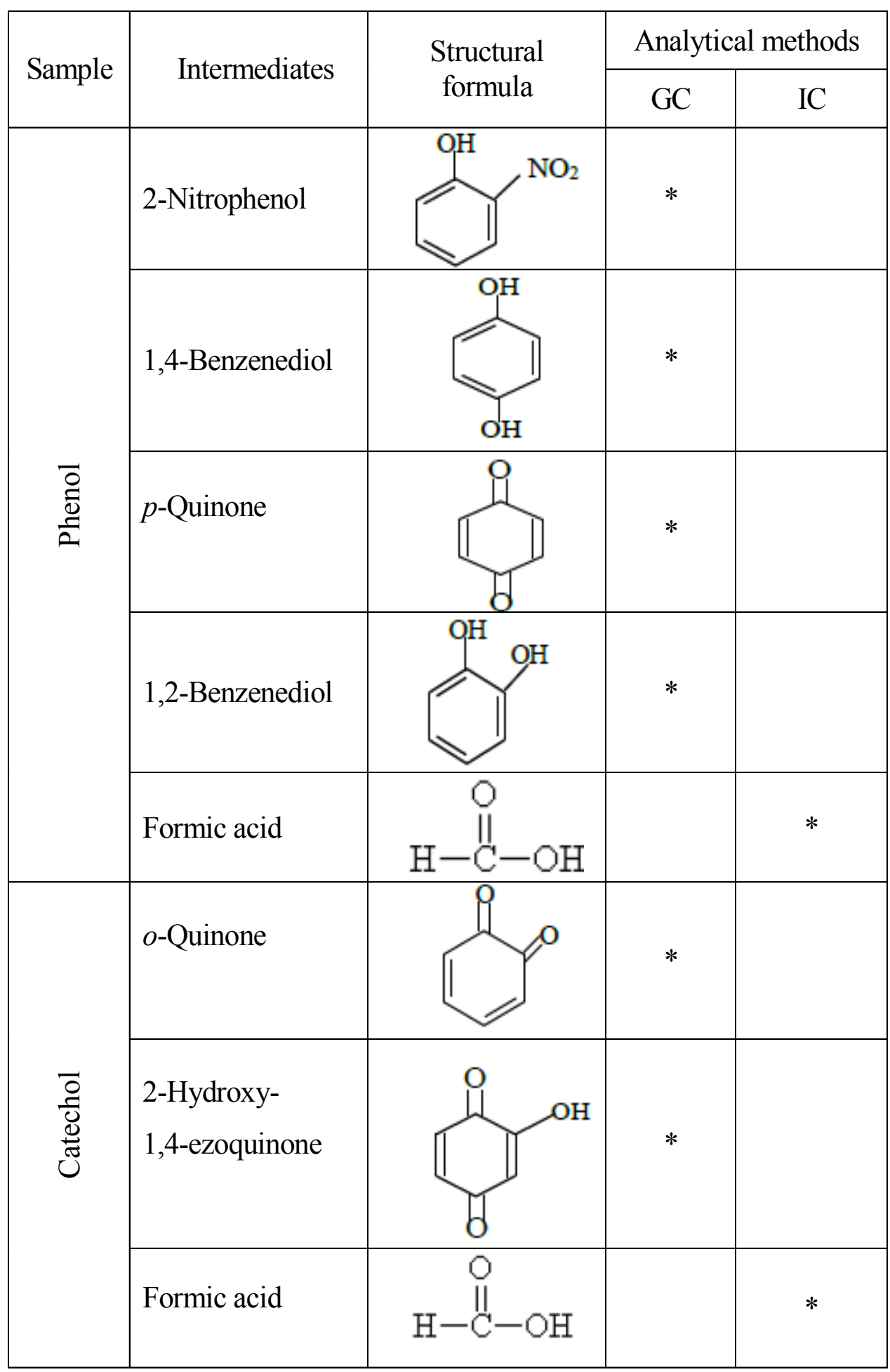


Table 2.(Contd.)

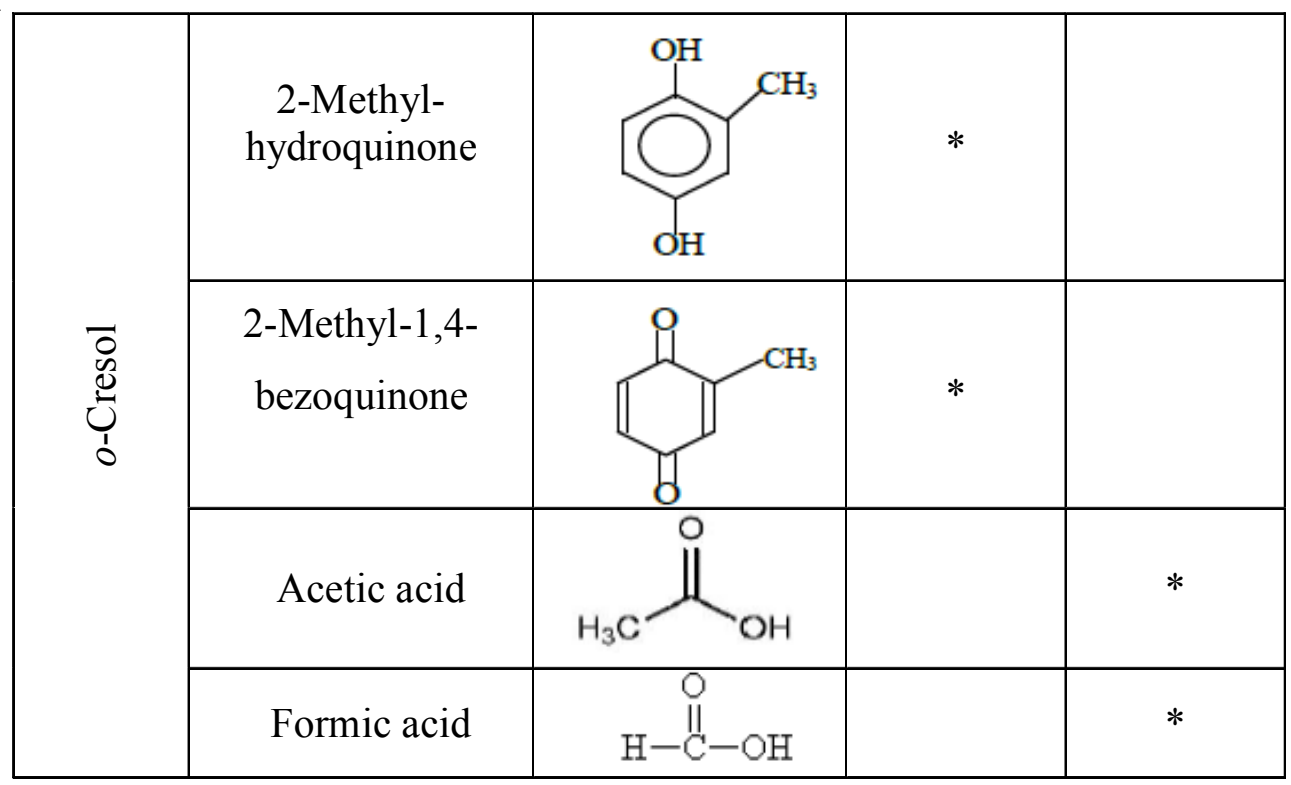

The electrophilic attack on phenol process preferentially on the positions orthoand para- to the phenolic $\mathrm{OH}$-group, thus forming catechol, hydroquinone, and 1,4-benzoquinone, which is consistent with the results shown here in the NTP reactor. In addition, when air was used as the carrier gas, 2-nitrophenol is detected in the solution, which may be produced from chemical reactions between phenol and NO*. All of the intermediates are finally oxidized to formic acid, oxalic acid, and acetic acid, when system has a sufficiently high $\mathrm{O}_{3}$ and $\mathrm{H}_{2} \mathrm{O}_{2}$ concentration generated during the discharge process. If the discharge time is long enough, the carboxylic acids such as formic and acetic acids are mineralized to $\mathrm{CO}_{2}$ and $\mathrm{H}_{2} \mathrm{O}$.

On the other hand, 2-hydroxy-1,4-bezoquinone, $o$-quinone and trace amounts of formic acid, along with other unidentified products were the primary intermediates of degradation of catechol (see Fig. 7, $b$ ). The main reactions of $\mathrm{OH}$ radicals with catechol are the addition of $\mathrm{OH}$ to various ring positions, forming the three different types of trihydroxycyclohexadienyl seen here [15, 24].

Ring-cleavage products are then continuously produced (i.e. diphenylmethanone and carboxylic acid groups), and then carboxylic acids are mineralized to $\mathrm{CO}_{2}$ and $\mathrm{H}_{2} \mathrm{O}$. Finally, the primary oxidation products of $o$-cresol (Fig. 7, c) are 2-methylhydroquinone, 2-methyl-1,4-bezoquinone, and trace amounts of formic, acetic, and maleic acids. As a result, the amount of intermediates decreases when the rings are more easily opened, leading to further oxidization into small molecules such as acetic and maleic acids, which were finally degraded to $\mathrm{CO}_{2}$ and $\mathrm{H}_{2} \mathrm{O}$. 

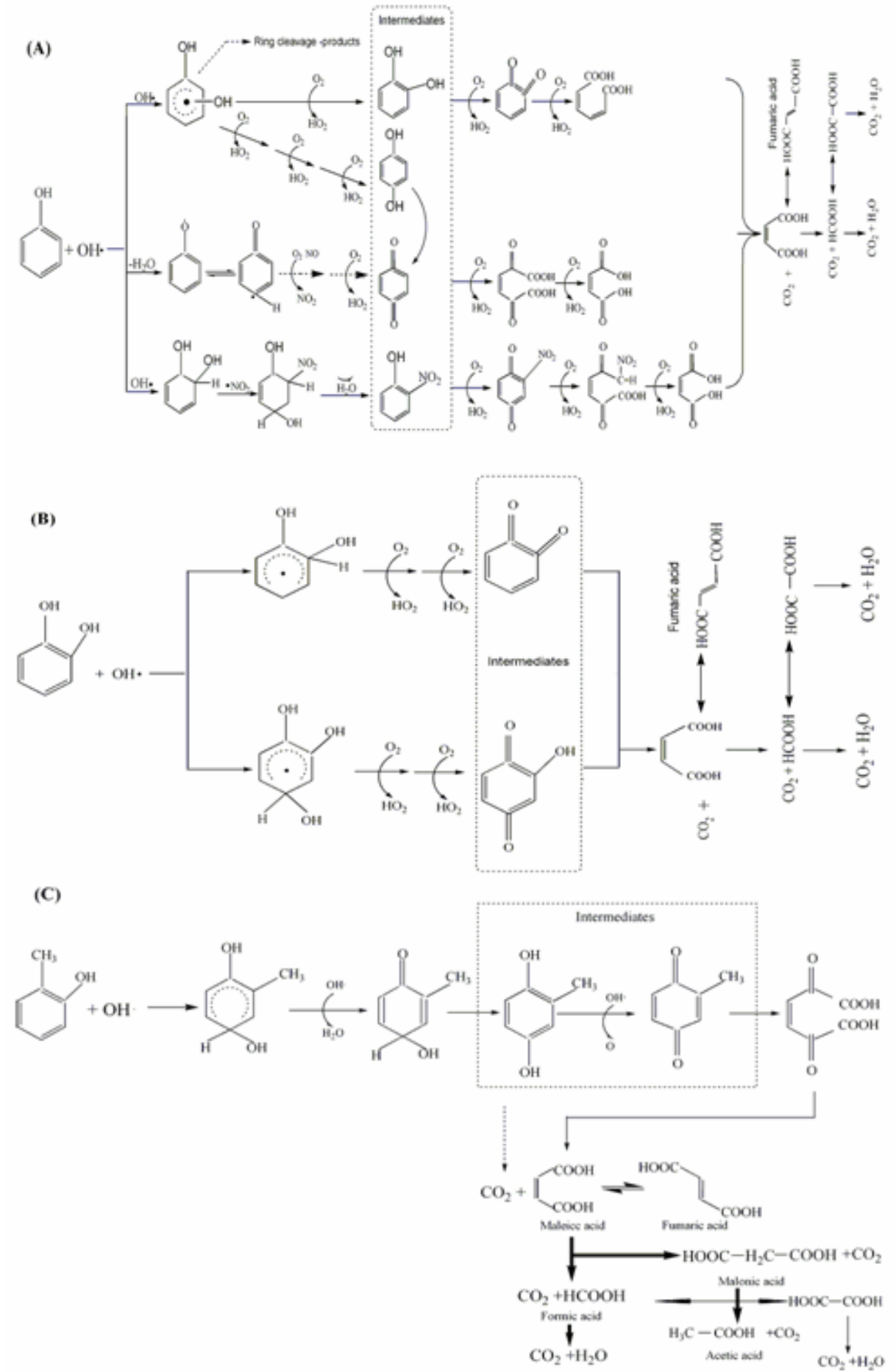

Fig 7. Decomposition pathway assumed for the degradation process of three phenols (a-phenol, $b$-catechol, $c$-o-cresol). 


\section{CONCLUSIONS}

Three phenols were successfully decomposed in a gas-liquid phase NTP using acorona discharge system. The short electrode gap, $1 \mathrm{~cm}$, gives a higher plasma energy density in the solution and improves the efficiency of phenol removal. It was found that the $\mathrm{H}_{2} \mathrm{O}_{2}$ concentration was increased in the discharge system when the oxygen content was increased. The discharge time was not long enough to effect complete mineralization, meaning $3 \mathrm{c}$ remains less than one. The efficiency of phenolic removal by COD was only $10-31 \%$ after $60 \mathrm{~min}$. With sufficient treatment time, it is possible to achieve the complete mineralization. Additionally, $\mathrm{OH}$ radicals have been shown to initiate the oxidation of the three phenols by identification of the intermediates. They were catechol, hydroquinone, 1,4-benzoquinone, 2-nitrophenol, 1,2-benzenedicarboxylic acid, diphenylmethanone, 2-methyl-hydroquinone, 2methyl-1,4-bezoquinone, and trace amounts of organic acids, along with additional unidentified compounds. The results also support that these intermediates were further oxidized by ring opening and transformed into small molecule substances such as acetic and maleic acids, which were finally degraded to $\mathrm{CO}_{2}$ and $\mathrm{H}_{2} \mathrm{O}$.

\section{References}

[1] Sugiarto A. T., Sato M. //Thin Solid Films. - 2001.- 386. - P. 295 - 299.

[2] Ighigeanu D. I., Calinescu I. I., Martin D. I., Matei C. I. //AIP Conf. Proc. (Istanbul, 2007). - Istanbul, 2007. - P. 780.

[3] Lei L., Zhang Y., Zhang X., Shen Y. J. // Electrostat.- 2008. - 66. - P. 16 - 24.

[4] Farrokhi M., Mesdaghinia A. R., Yazdanbakhsh A. R., Nasseri S. //Iran. J.Environ. Health. - 2004. - 1. - P. $12-18$.

[5] Chen Y. S., Zhang X. S., Dai Y. C., Yuan W. K. // Sep. Purif. Technol. - 2004. 34. - P. $5-12$.

[6] Chang J. // J. Sci. Technol. Adv. Materials. - 2001. - 2. - P. 571 - 576.

[7] Hernandez R., Zappi M., Colucci J., Jones R. // J. Hazard. Materials. 2002. - 92. - P. 33 - 50.

[8] Lukes P., lupek M., Babicks V., Unka P., Winterovs G., Janda V. //Acta Phys.Slovaca. - 2003. - 53. - P. 423 - 428.

[9] Hao X.L., Zhou M.H., Zhang Y., Lei L.C.// Plasma Chem. Plasma Process. 2006. - 26. - P. 455 - 468.

[10] Sun B., Sato M., Clements J. S. // Environ. Sci. and Technol. - 2000. - 34. P. $509-513$.

[11] Hao X.L., Zhou M.H., Lei L.C. // J. Hazard. Materials. - 2007. - 141. - P. $475-482$.

[12] Pacheco M. J., Morao A., Lopes A., Ciriaco L., Goncalves I. // Electrochim. Acta. - 2007. - 53. - P. 629 - 636.

[13] Wang L., Jiang X. J. // Hazard. Materials. - 2009. -161. - P. 926 - 932.

[14] Sun B., Sato M., Clements J. S. // J. Electrostat. - 1997. - 39 . - P. 189 - 202. 
[15] Yan J.H., Du C.M., Li X.D., Sun X.D., Ni M.J., Cen K.F., Cheron B. // Plasma Sources Sci. Technol. - 2005.- 14. - P. 637 - 644.

[16] Wang J., Mei Y., Liu C., Chen J. // J. Environ. Sci. - 2008. - 20. - P. 1306 1311.

[17] Sunka P., Babicky V., Clupek M., Lukes P., Simek M., Schmidt J., Cernak M. // Plasma Sources Sci. Technol. - 1999. - 8. - P.258 - 265.

[18] Lukes P., Appleton A. T., Locke B. R. // IEEE Trans. Ind. Appl. - 2004. - 40. P. $60-67$.

[19] Hoeben W. F. L. M., van Veldhuizen E. M., Rutgers W. R., Cramers C. A.M.G., Kroesen G. M. W. // Plasma Sources Sci. Technol. - 2000. - 9. - P. 361 - 369.

[20] Shin W. T., Yiacoumi S., Tsouris C., Dai S. // Ind. Eng. Chem. Res. - 2000. 39. - P. $4408-4414$.

[21] Grymonprs D. R., Finney W. C., Clark R. J., Locke B. R. // Ibid. - 2003. 42, - P. $5117-5134$.

[22] Lukes P., Locke B. R. // Ind. Eng. Chem. Res. - 2005. - 44. - P. 2921 - 2930.

[23] Lukes P., Locke B. R. J. // Phys. D: Appl. Phys. - 2005. - 38. - P. 4074 4081.

[24] Kubesch K., Zona R., Solar S., Gehringer P. // Radiat. Phys. Chem.- 2005. 72. - P. $447-453$. 